\title{
The oxygenation module: the missing link in using sleep apnea devices to treat COVID-19 pneumonia at home
}

\author{
Dmitrijs Bliznuks ${ }^{*}$ (D), Svjatoslavs Kistkins², Jevgēnijs Teličko ${ }^{3}$, Vadims Geža ${ }^{3}$, Girts Zāğeris ${ }^{3}$, Artis Svaža ${ }^{4}$, \\ Emil Syundyukov ${ }^{5}$, Mārtinš̌ Purenkovs², Dana Zeme², Solveiga Jēkabsone ${ }^{2}$, Dace Žentiña ${ }^{2}$, Valdis Pīrāgs ${ }^{2}$ and \\ Immanuels Taivans ${ }^{2}$
}

${ }^{*}$ Correspondence:

dmitrijs.bliznuks@rtu.Iv

${ }^{1}$ Institute of Smart

Computer Technologies,

Riga Technical University,

2-335 Daugavgrivas street,

Riga 1658, Latvia

Full list of author information

is available at the end of the

article

\begin{abstract}
Background: The study aims at solving the problem with the limitations of the homecare CPAP equipment such as sleep apnea devices in the treatment of COVID-19 pneumonia. By adding an advanced, rapid-to-produce oxygenation module to existing CPAP devices we allow distributing healthcare at all levels, reducing the load on intensive care units, promoting treatment in the early stages at homecare. A significant part of the COVID-19 pneumonia patients requires not only an oxygen supply but also additional air pressure. Existing home care devices are able to create precise positive airway pressure, but cannot precisely measure supplied oxygen concentration. Either uses uncertified and potentially unsafe mechanisms.
\end{abstract}

Results: The developed system allows using certified and widely available CPAP (constant positive airway pressure) devices to perform the critical function of delivering pressure and oxygen to airways. CPAP device is connected to the designed add-on module that can provide predefined oxygen concentration in a precise and stable manner. Clinical test results include data from 12 COVID-19 positive patients. The device has been compared against certified NIV (non-invasive) equipment under 6-20 $\mathrm{hPa}$ pressure and $30-70 \% \mathrm{FiO}_{2}$. Tests have proved that the developed system can achieve the same $\mathrm{SaO}_{2}(p=0.93)$ and $\mathrm{PaO}_{2}(p=0.80)$ levels as NIV with clinically insignificant differences. Test results show that the designed system can substitute NIV equipment for a significant part of COVID-19 patients while leaving existing NIV devices for unstable and critical patients. The system has been designed to be massproduced while having medically certified critical components.

Conclusion: The clinical testing of the new device for oxygen supplementation of patients treated using simple CPAP devices looks promising and could be used for the treatment of COVID-19 pneumonia.

Keywords: Sleep apnea, COVID-19, Critical Care, Non-invasive ventilation, Homecare author(s) and the source, provide a link to the Creative Commons licence, and indicate if changes were made. The images or other third party material in this article are included in the article's Creative Commons licence, unless indicated otherwise in a credit line to the material. If material is not included in the article's Creative Commons licence and your intended use is not permitted by statutory regulation or exceeds the permitted use, you will need to obtain permission directly from the copyright holder. To view a copy of this licence, visit http:// creativecommons.org/licenses/by/4.0/. The Creative Commons Public Domain Dedication waiver (http://creativecommons.org/publi cdomain/zero/1.0/) applies to the data made available in this article, unless otherwise stated in a credit line to the data. 


\section{Background}

In the majority of cases, COVID-19 runs with inflammation in the upper airways and manifests with symptoms like dry cough, subfebrile or febrile temperature, and resolves in several days. Some patients [1] develop pneumonia with symptoms of hypoxia and decreased level of $\mathrm{SpO}_{2}$. Therefore, the management of COVID-19 caused type 1 respiratory failure patients includes the administration of additional oxygen and prevention of distal airway and alveolar collapse $[2,3]$. These options can be maintained by using non-invasive ventilation (NIV) applying positive end-expiratory pressure (PEEP). The existing intensive care NIV devices and high flow nasal cannula (HFNC) currently are used in treatment type 1 respiratory failure in patients with COVID-19 pneumonia [4-6]. However, shortages in the number of available NIV or HFNC, as well as high costs of the devices, provide several significant limitations, especially during the outbreak when time and expenses are crucial [7]. For this purpose, a cheap and rapidly produced solution must meet the criteria of clinical efficacy similar to the efficacy of NIV or HFNC.

The simplest way to promote PEEP is to use devices that are designed for the treatment of sleep apnea syndrome-continuous positive airway pressure (CPAP) devices that keep slightly positive pressure in airways, so preventing airways collapse at the end of expiration. These instruments also allow the administration of additional oxygen by introducing it into the inspiratory port or directly into the face mask [8].

However, this oxygen administration does not allow precise measurement of oxygen concentration in inhaled air because of fluctuations of oxygen level due to continuous air movements in the inspiratory port. At the same time a proper oxygen concentration is significant for the calculation of alveolar-arterial gradient for oxygen, which is an indicator of permeability of the alveolo-capillary membrane, or in other words-an indicator of the level of lung respiratory function loss. Continuous measurement of this index allows monitoring the clinical condition, providing rapid response in deterioration of the disease [9].

Therefore, we have created the add-on device for CPAP instruments allowing us to deliver the precise oxygen concentration to the patient. The study aimed to modify CPAP devices and clinically investigate the efficacy of the proposed solution by comparing it with current existing NIV devices.

During the COVID-19 pandemic there was a rapidly increased demand on ICU facilities, especially mechanical lung ventilators (MVL). The shortage of MLV raised the question of early CPAP treatment in COVID-19 pneumonia patients. In CPAP, additional pressure is provided to the alveoli, which prevents them from collapsing at the end of the exhalation [1,2]. This results in improved gas exchange, reduced breathlessness, and respiratory rate. Also, CPAP might protect the patient from the further progression of lung damage and lower the tracheal intubation rate. In addition, it is possible to reduce oxygen concentrations $\left(\mathrm{FiO}_{2}\right)$ in the inhaled air by using positive pressure, thereby minimizing the toxic effects of oxygen and utilizing oxygen capacity more cost-effectively [3, 4]. Until the beginning of the COVID-19 pandemic, CPAP equipment was used to treat obstructive sleep apnoea at home. The use of CPAP devices is now also introduced for the treatment of acute patients in hospitals [5]. The amount of oxygen to be delivered by the CPAP can only be controlled by the 
oxygen supply rate following the CPAP device. This may help the medics decide on the future respiratory failure therapy tactics for a patient with hypoxaemia, thereby making CPAP a promising option in a hospital setting.

The idea of the study is based on the results of early CPAP therapy described in a study published by BMJ Open Respir Res [5]. In Fig. 1, the probability of survival was rapidly reduced after day 4 of treatment for patients included in the study.

It's worth noting diabetes and arterial hypertension as risk factors for disease progression. The study compared mortality in patients who received CPAP therapy at the early phase of the disease (before the seventh day) and at late phase (after the seventh day). Mortality appeared to have decreased significantly in patients with diabetes (19\% vs $43 \%$ ) and arterial hypertension (8 vs $26 \%$ ). The rapid progression of the disease correlated with the radiological scene of pneumonia when the groundglass phase (days 1-6) transforms into the reticulation phase (7-14). Early treatment with CPAP was also described in other studies $[6,7]$ as well as in editorial letters[8]. The letter to ERJ Journal [9] noted the stratification of patients was made based on radiological manifestation, also the majority of patients received relatively early (days 3-10) CPAP therapy. Although studies prioritize non-invasive lung venting (NIV) treatment, it is still challenging to identify technical parameters and inclusion criteria that would influence the outcome [10-12].

For example, researchers correlate high levels of $\mathrm{FiO}_{2}(0.4-0.8)$ or high oxygen use (>10 L/min) before using NIV with higher mortality (OR 1.59) [13, 14]. In turn, for those who used non-invasive ventilation with lower $\mathrm{FiO}_{2}$ support, mortality decreased [15]. RECOVERY-RS, one of the most important studies, compared conventional oxygen therapy and HFNC with CPAP [16].Currently, the new data from RECOVERY-RS has been published in the preprinted form and is awaiting comments from reviewers. However, taking into account all the above data, the results show that the CPAP group has significantly lower mortality and a transition to MLV compared to conventional or HFNC therapy.

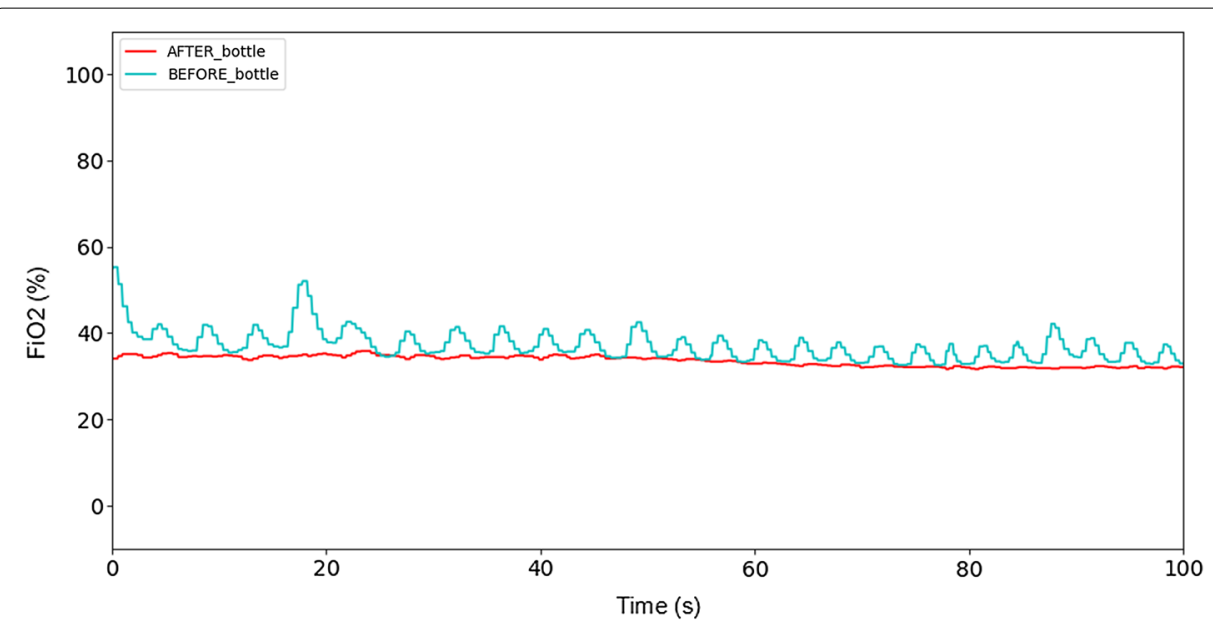

Fig. $1 \mathrm{FiO}_{2}$ measurements in two oxygen sensor locations: before (blue line) and after (red) the buffer tank under $6 \mathrm{hPa}$ pressure 


\section{Results}

\section{Bench testing}

As shown in the methods section, after performing numerical simulations of oxygen mixing performance, the final design with the buffer tank has been used for building a prototype. In Fig. 1 oxygen concentration with and without buffer tank can be seen. The resulting oxygen concentration fluctuations with a buffer tank were $<1 \%$.

The plot has been obtained by using a prototype device set at $6 \mathrm{hPa}$ positive pressure and a healthy person. While the mask is properly attached and there are no breathing abruptions, the system could keep oxygen concentration accuracy within $1 \%$, even if the character of the patient's breathing changes. Without a buffer tank oxygen concentration changes according to breathing frequency. Right after switching the system or after reapplying the mask, it might take up to a minute, while concentration reaches the desired level and stabilizes. Such effects do not affect therapy and are acceptable as seen in the clinical results section below.

\section{Clinical testing in patients with COVID-19 pneumonia}

Totally 16 patients with COVID-19 pneumonia have been enrolled on a clinical trial and 12 of them have been included. The characteristics of patients included in a clinical trial are shown in the table below. Two patients have been excluded due to intolerance to a face mask, while the third patient has been expelled due to clinical deterioration receiving primarily only NIV. The fourth patient has been excluded due to arterial catheter thrombosis.

To compare the effectiveness of the new oxygen supply system $(\mathrm{CPAP}+)$ with a standard non-invasive ventilator (NIV) we used a repeated-measures analysis of variance (ANOVA).

Figure 2A allows comparing necessary concentrations of oxygen in the inhalation line $\left(\mathrm{FiO}_{2}\right)$ which were set on two devices to keep the stable oxygen saturation $\left(\mathrm{SaO}_{2}\right)$. The Fig. 2 shows that $\mathrm{FiO}_{2}$ levels did not differ significantly in the majority of patients. Only in two cases when changing from one instrument to another different oxygen concentration had to be set. Figure $2 \mathrm{~B}$ reflects the levels of carbon dioxide measured in arterial blood $\left(\mathrm{PaCO}_{2}\right)$ Graph shows that two patients, P7 and $\mathrm{P} 10$ had $\mathrm{CO}_{2}$

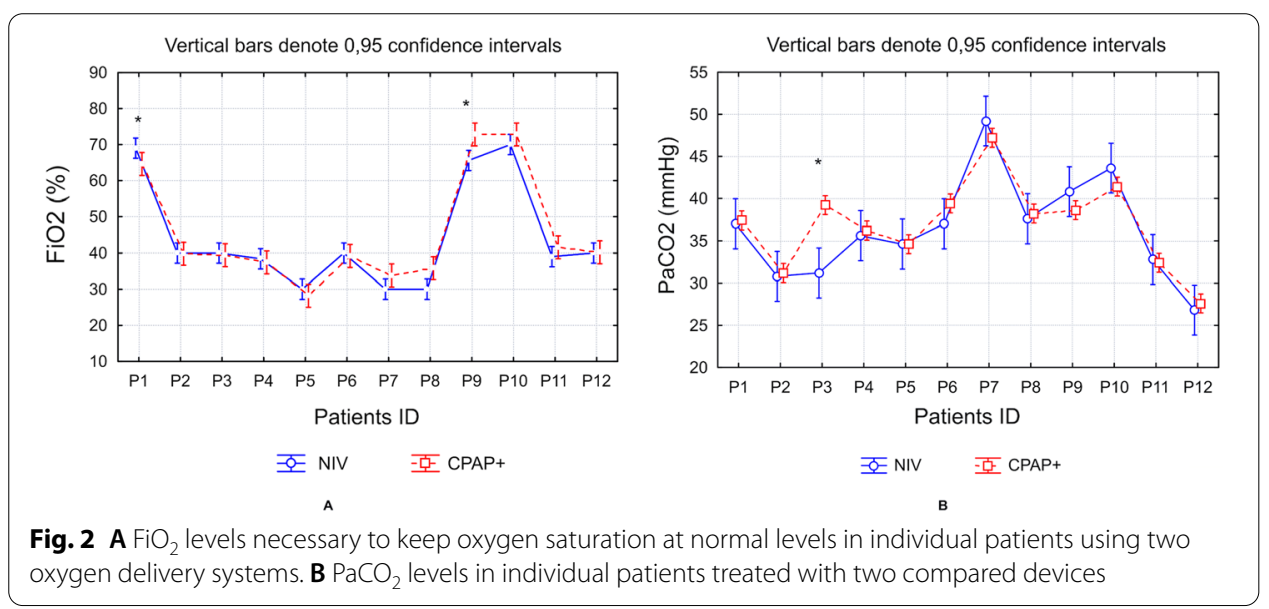


concentrations above $40 \mathrm{mmHg}$, indicating carbon dioxide retention. At the same time breathing with aid of any of both devices did not change high $\mathrm{CO}_{2}$ values. A significant difference between $\mathrm{CO}_{2}$ values (Fig. $2 \mathrm{~B}$ ) in patient 3 probably occurred due to hypocapnia induced by hyperventilation and did not depend on the device used.

Most precisely the effectiveness of oxygen supplementation may be checked by analyzing arterial blood gases. The most sensitive index is partial oxygen pressure. Figure 3A, B demonstrate partial pressure of oxygen in arterial blood $\left(\mathrm{PaO}_{2}\right)$ levels in individual patients being connected to both tested devices. Significant differences in $\mathrm{PaO}_{2}$ and $\mathrm{SaO}_{2}$ levels have been presented only in two patients. In these cases, a lower level of $\mathrm{PaO}_{2}$ has been observed in the trial with the CPAP+ device. However, as can be seen from the graph, in other patients the situation can be the oppositehigher levels of $\mathrm{PaO}_{2}$ with CPAP+ device. Taken together, the comparison between two devices in all patients cohorts show no significant differences between $\mathrm{PaO}_{2}$ and $\mathrm{SaO}_{2}$ values (Fig. 3C, D).

The necessary $\mathrm{FiO}_{2}$ for each patient depended on the severity of their disease. A precise indicator of the effectiveness of gas exchange is the alveolar-arterial gradient of oxygen $\left(\mathrm{AaDO}_{2}\right)$. Figure 4 shows the regression analysis between $\mathrm{FiO}_{2}$ and alveolararterial gradient. Graphs representing data obtained with both devices (NIV-Fig. 4A; CPAP +-Fig. 4B) show high predictiveness levels.

Summary of significant differences between most important indices measured in two trials is presented in Table 1 , showing $p$ values. The full table of all measured and calculated indices is available in Annex.

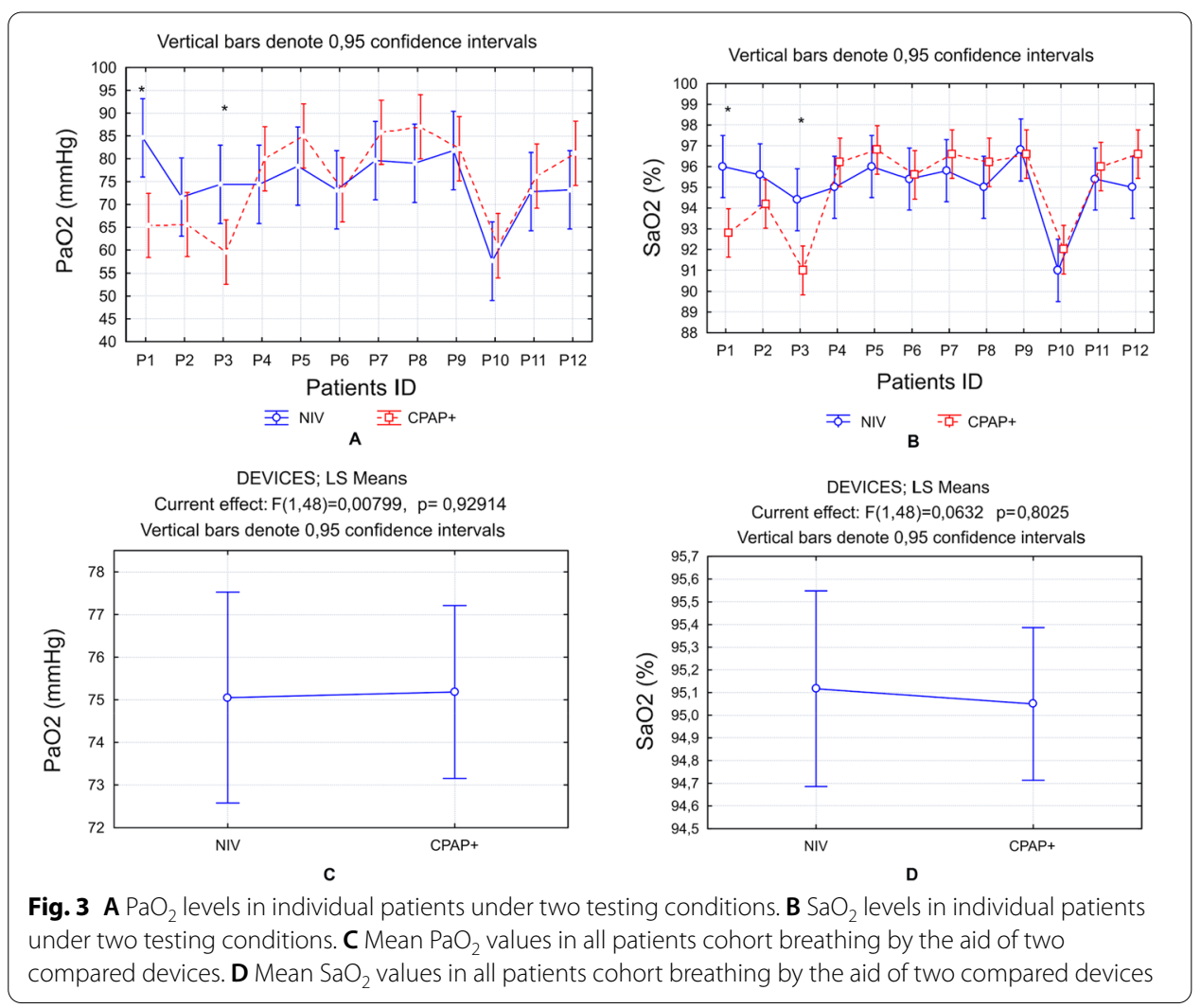




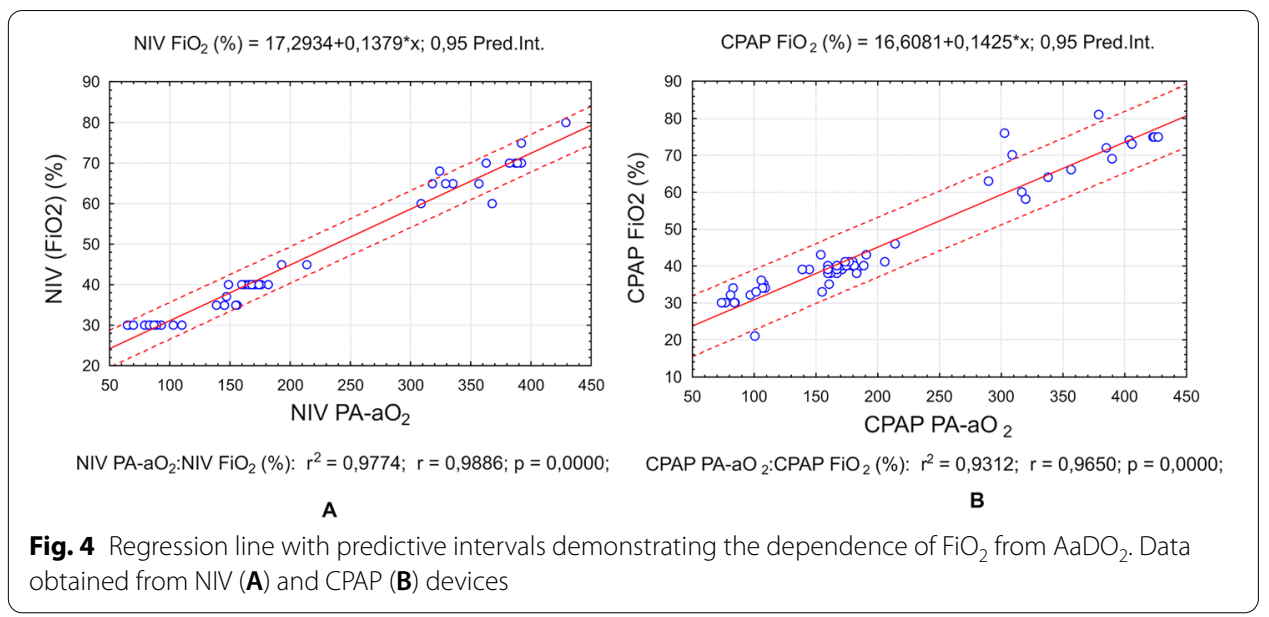

Table $1 p$-values characterizing the differences between the mean values of indices measured using NIV and CPAP + instruments in individual patients

\begin{tabular}{llllll}
\hline Pac. ID & $\mathrm{FiO}_{2}$ & $\mathrm{SaO}_{\mathbf{2}}$ & $\mathrm{PaO}_{\mathbf{2}}$ & ${\mathrm{PA}-\mathrm{aO}_{2}}$ & $\mathrm{PaCO}_{\mathbf{2}}$ \\
\hline P1 & $\mathbf{0 . 0 5 0}$ & $\mathbf{0 . 0 0 1}$ & $\mathbf{0 . 0 0 1}$ & 0.136 & 0.801 \\
P2 & 0.927 & 0.134 & 0.251 & 0.765 & 0.801 \\
P3 & 0.785 & $\mathbf{0 . 0 0 1}$ & $\mathbf{0 . 0 0 6}$ & 0.787 & $\mathbf{0 . 0 0 0 1}$ \\
P4 & 0.649 & 0.198 & 0.284 & 0.722 & 0.704 \\
P5 & 0.414 & 0.388 & 0.208 & 0.570 & 1.000 \\
P6 & 0.716 & 0.829 & 1.000 & 0.776 & 0.135 \\
P7 & 0.088 & 0.388 & 0.236 & 0.119 & 0.211 \\
P8 & $\mathbf{0 . 0 1 1}$ & 0.198 & 0.128 & $\mathbf{0 . 0 2 2}$ & 0.705 \\
P9 & $\mathbf{0 . 0 0 2}$ & 0.829 & 0.939 & 0.755 & 0.170 \\
P10 & 0.206 & 0.282 & 0.514 & 0.190 & 0.170 \\
P11 & 0.240 & 0.517 & 0.514 & 0.272 & 0.801 \\
P12 & 0.927 & 0.088 & 0.128 & 0.842 & 0.614 \\
\hline Values indicating significant differences are marked with bold & & &
\end{tabular}

\section{Discussion}

The results of this study showed no statistically significant clinical differences between NIV and modified CPAP+, proposing a further discussion regarding the cost-effectiveness of the solution during the state of emergency.

It would be appropriate to compare currently existing three available types of devices in CPAP mode: the authors proposed home-care APAP/CPAP modification in comparison with two types of NIV device: hospital equipment and both hospital/home care devices.

In the table below (Table 2), CPAP+ modification is 4 to 15 times cheaper than alternative solutions. As the clinical study shows, device efficiencies are statistically similar to ICU-NIV. It is worth mentioning that the CPAP modification has been clinically tested with only $\mathrm{FiO}_{2}<70 \%$ while ICU-NIV equipment reaches $100 \%$ oxygen concentration. However, preclinical results showed $\mathrm{FiO}_{2}>95 \%$. It must be taken into account that we have aimed to develop a cost-effective device that can reduce the load on existing ICUNIV devices. 
Table 2 Comparison of three available types of devices in CPAP mode

\begin{tabular}{|c|c|c|c|}
\hline & Our CPAP + device & $\begin{array}{l}\text { NIV in } \\
\text { hospitals } \\
\text { (ICU-NIV) }\end{array}$ & NIV in hospitals + home care \\
\hline Full set price in EUR & 800 & $10,000-13,000$ & $3000-7000$ \\
\hline $\begin{array}{l}\text { Oxygen supply from the central gas } \\
\text { system without a flow meter }\end{array}$ & + & + & - \\
\hline $\begin{array}{l}\text { Oxygen supply from the central gas sys- } \\
\text { tem with a flow meter, up to } 15 \mathrm{l} / \mathrm{min}\end{array}$ & + & + & + \\
\hline $\begin{array}{l}\text { Oxygen supply from low-pressure oxygen } \\
\text { concentrators }\end{array}$ & + & - & + \\
\hline Maximal achievable $\mathrm{FiO}_{2}$ & $70 \%-95 \%$ & $100 \%$ & Depending on PEEP \\
\hline $\begin{array}{l}\text { Oxygen concentration is displayed on a } \\
\text { screen }\end{array}$ & + & + & - \\
\hline $\begin{array}{l}\text { Ability to control and regulate oxygen } \\
\text { concentration independently from the } \\
\text { applied pressure }\end{array}$ & + & + & - \\
\hline $\begin{array}{l}\text { Necessary technical and electrical safety } \\
\text { checks }\end{array}$ & Once a year & Once a year & Not required \\
\hline
\end{tabular}

The proposed benefits of the modification of the home CPAPs may be defined as low costs per one unit (800 EUR per home CPAP and add-on comparing to 10,000 EUR per ICU-NIV); rapid production and distribution (2-3 weeks vs $3-5$ months); redirection of home-CPAP devices for the use in chronic conditions, such as sleep apnea after the outbreak. The potential cost-effectiveness may be significantly higher if the sleep apnea device could be rearranged for the patients that are primarily diagnosed with OSA. At the same time, strategic reserves of CPAP devices may be stored in hospitals to be ready for the new wave.

Industrial enterprises and scientists also tried to succeed in development of low-cost ventilators [11-15]. Despite the fact that Garmendia et al. [16] designed and clinically tested even much cheaper CPAP machines proposing 70-80 EUR instead of 600 EUR, the next study shows that early CPAP intervention could result in a potentially viable treatment option for patients only during the first days of hospitalisation [17]. Garmendia's CPAP device could be used in the early stage of the disease while moderate requires significant additional oxygen therapy [18]. Pandor et al. previously compared the costeffectiveness of the prehospital-CPAP without a proper oxygen delivery arguing that the results of the study were uncertain [19]. The proposed additional solution may enhance the efficacy of the Garmendia CPAP devices, providing even cheaper analogues of NIV devices for more severe patients requiring higher oxygen concentration.

During the first outbreak Engineers of UK Formula 1 have developed a CPAP machine with the distribution of oxygen and positive airway pressure to patients $[20,21]$. The F1 CPAP device mixes gases in a proper concentration based on the Venturi effect thus resulting in a proper gas formation with much predictable $\mathrm{FiO}_{2}$ concentration. However, this device also requires an additional outsourced oxygen sensor and a pressure valve promoting $15-20 \mathrm{mmH}_{2} \mathrm{O}$ pressure. A cost-effective solution met several disadvantages such as high oxygen expenditures due to the construction of the equipment with a further load on the oxygen supply chain in the hospital. A high oxygen expenditure promotes overload of hospital medical gas system [22, 23]. As the experience showed, 
frequently CPAP equipment can be used at home, additionally relieving the medical infrastructure [24, 25]. Moreover, it facilitates saving of financial means, because the acquisition of a large number of intensive therapy lung ventilators is not needed. For this purpose the proposed CPAP modification can use an external oxygen delivery system such as oxygen concentrators, reducing the load on the oxygen supply chain in the hospital.

Despite the advantage of this method of oxygen delivery there were some observations and raising questions about the usage of the device and its operation:

As mentioned in the previous sections, the device has accuracy limitations during sudden flow changes, for example reapplying the mask. The device buffer tank volume has been calculated to smooth fluctuations during inhale and exhale phase when flow change stays below a certain limit. If the mask is removed, flow increases rapidly and since oxygen flow is limited, the buffer is emptied fast and oxygen concentration drops below a predefined level. The same effects could be observed if the mask is not applied properly and there are occasional false-air situations. Existing NIV devices premix oxygen before performing pressure/flow control therefore can keep constant concentrationindependent to the mask application.

Other limitations of the developed system include the inability to transport patients since the device has no autonomous power source. The device is not delivering additional breathing measurements like ICU ventilator: tidal volume, minute ventilation, peak pressure, flow, volume, and pressure waves. The current design requires significant time to dismount air pathways for sterilization. Nevertheless, sterilization by using special gases is possible.

Clinical testing of the new CPAP supplemental oxygen delivery system has shown that this device allows enriching the air with oxygen up to 70\% during CPAP therapy (higher concentrations have only been tested pre-clinically). Comparison with a standard noninvasive ventilator (NIV) working in CPAP mode has shown that most important indices of gas exchange, like $\mathrm{PaO}_{2}$ and $\mathrm{PaCO}_{2}$, did not change significantly when switching the patients from breathing with aid of NIV instrument to CPAP+.

Two cases (P1 and P3) showing significant differences in $\mathrm{PaO}_{2}$ between two devices evidently have been connected with changes in the patient's condition and did not depend on the instrument. Testing of the patient P1 was started with NIV instrument. $\mathrm{FiO}_{2}$ level was set on $80 \%$ oxygen that corresponded to previous necessary level for this patient. After 15 min breathing arterial $\mathrm{PO}_{2}$ level raised to $102 \mathrm{mmHg}$ and saturation to $98 \%$ that was obviously too high. Therefore, $\mathrm{O}_{2}$ concentration was corrected to the level of $70 \%$ and thereafter to $60 \%$. By the end of the test period $\mathrm{PaO}_{2}$ was $70 \mathrm{mmHg}$ and $\mathrm{SaO}_{2}-94 \%$. Testing with $\mathrm{CPAP}+$ instrument was started with $\mathrm{FiO}_{2}$ level of $60 \%$ and gradually raised to $65 \%$ to keep the $\mathrm{O}_{2}$ saturation at optimal level. These changes explain statistically significant differences between mean $\mathrm{PaO}_{2}$ values in these two trials. The situation was similar with patient P3.

The patient's need for additional oxygen changes over time. Most likely cause is the ventilation/perfusion mismatch that occur with changing the position of the chest [26].

Significantly lower levels of $\mathrm{PaCO}_{2}$ in patient 3 when breathing through a NIV device, are likely to be associated with anxiety-induced hyperventilation at the start of the experiment. This was also reflected in the respiratory rate which was higher at the 
beginning of the test. When treated with CPAP+device, the patient was calm and his $\mathrm{PCO}_{2}$ level was in the normal range.

\section{Conclusions}

The results of this study showed no statistically significant clinical differences between $\mathrm{NIV}$ and modified CPAP+in case of $\mathrm{FiO}_{2}<70 \%$. Elaborated oxygen supplementation module expands the range of COVID-19 patients to be treated with CPAP devices. This solution is significantly cheaper than NIV devices and can be used in both hospital and home settings. Further clinical studies are necessary to provide long-term safety and efficacy data before the system is applied to routine clinical practice.

\section{Methods}

\section{Ventilator description}

The proposed device has been designed as an add-on to the CPAP device that is certified to provide an automatically controllable air pressure supply to the patient. The overall scheme of the modified system is shown below in Fig. 5A.

The device allowed controlling oxygen supply to the patient's inhaled air in the $\mathrm{FiO}_{2}$ range of $21 \%$ to $95 \%$. Supplied air pressure and moisture have been controlled by a certified CPAP device. During the development stage, two versions of the CPAP add-on have

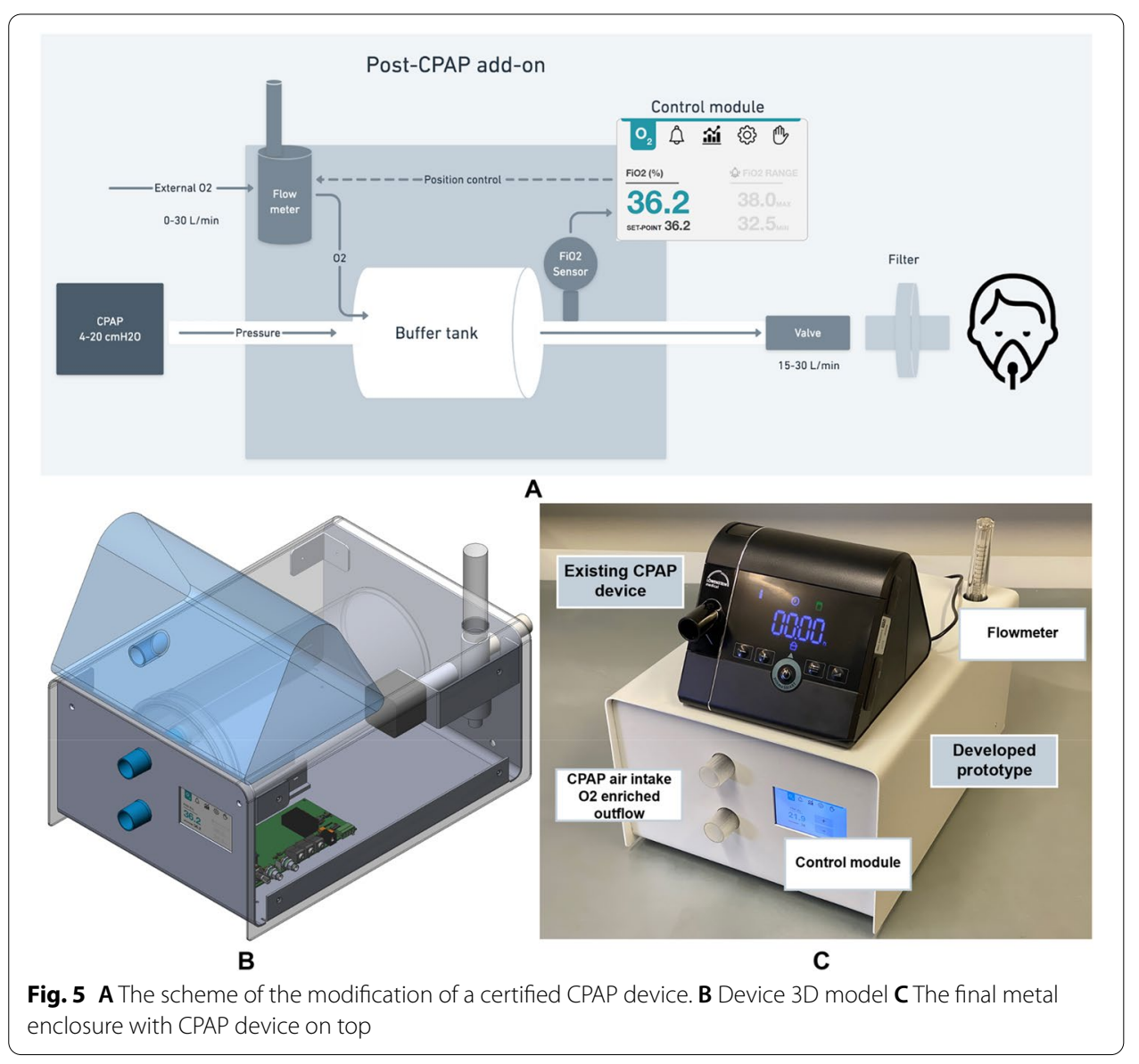


been designed: draft prototype to prove the concept (Fig. 5B) and final prototype ready to be mass-produced (Fig. 5C).

The microcontroller-based system monitors oxygen concentration at the output of the tank and adjusts the oxygen supply to keep the $\mathrm{FiO}_{2}$ at the set level. Clinicians can see the current $\mathrm{FiO}_{2}$ level on the LCD touchscreen and can change it according to therapy. The device has alarm and logging capabilities to monitor patients' condition and store data for further analysis. The device applies to Type B (Body) class- "No direct physical contact with the patient". And to the product class IIA as for "Directive 93/42/EEC". The device served as an add-on to the existing certified CPAP equipment (eg. Löwenstein medical Prisma Smart). The add-on has been electrically operated, with no direct contact with patients or operators (health care personnel). Oxygen flow control has been provided by using a medical-grade flow meter as an intermediate device. Stepper motor was used to rotate the flowmeter valve that in a result changes oxygen flow. Stepper motor is controlled by software PID controller that uses $\mathrm{FiO}_{2}$ sensors data for feedback. To make sure that sensors readings are correct, two $\mathrm{FiO}_{2}$ sensors were used and if the difference in their reading was larger than threshold, system gave an alarm.

To obtain a controllable oxygen supply to the patient, it is essential to do precise measurements of oxygen concentration in the flow. However, oxygen concentration may vary significantly across the cross-section of the flow channel (pipe) if gases are not premixed. For this reason, numerical simulations were carried out for different mixing setups to establish a flow where oxygen concentration is precisely measurable. The simplest way to supply oxygen is to make a straight oxygen pipe connection to the main CPAP flow channel. Numerical simulation results of oxygen concentration reveal high inhomogeneity. X-type mixer appropriately performs in the terms of oxygen homogeneity, but it greatly increases hydraulic resistance $(+15 \%)$. Similar questions have also been raised in literature adding a viral/bacterial filter proximally to patient [10]. To deal with this problem, a custom mixer has been designed that allowed mixing oxygen with homogeneity $>99.5 \%$ and low hydraulic resistance $(+5 \%)$. An additional challenge for the add-on device creation was reaching stable concentration levels of oxygen at any breath phase. That was achieved by the incorporation of a buffer tank into the inhalation line. Multiple simulations have been performed to find an optimal volume and shape of the tank.

\section{Ventilator testing in patients with COVID-19 pneumonia}

The clinical testing of the new device has been realized by comparing the efficiency and safety of the new CPAP supplemental oxygen delivery system with the efficiency of a non-invasive ventilator (NIV) in the CPAP/PEEP mode. Two Intensive care ventilators have been used-Philips Respironics V60 and Maquet Servo-AIR in CPAP mode for one hour and then changed therapy to APAP Lowenstein medical Prisma Smart connected to newly made extra oxygen delivery device.

Hypoxaemic patients, who received just oxygen therapy or NIV therapy in CPAP mode have been included in the study.

The study was evaluated and received permission from the local Ethics committee of the PSCUH. Patients have been informed that a catheter will be inserted into their artery to get blood samples. The patient's characteristics are given in Table 3. 
Table 3 Patients' data

\begin{tabular}{lllllll}
\hline Patient ID & Gender & Age, years & $\mathbf{S p O}_{\mathbf{2}}$ & $\mathbf{A a D O}_{\mathbf{2}}$ & $\mathbf{P a C O}_{\mathbf{2}}$ & PEEP $^{-}$ \\
\hline P1 & M & 80 & 95 & 372 & 37 & 5 \\
P2 & M & 77 & 94 & 175 & 31 & 5 \\
P3 & M & 63 & 94 & 171 & 31 & 9 \\
P4 & M & 44 & 97 & 155 & 36 & 5 \\
P5 & M & 42 & 95 & 92 & 35 & 6 \\
P6 & M & 44 & 95 & 165 & 37 & 5 \\
P7 & F & 33 & 98 & 73 & 48 & 6 \\
P8 & M & 53 & 96 & 87 & 38 & 5 \\
P9 & M & 53 & 95 & 333 & 41 & 7 \\
P10 & M & 62 & 92 & 388 & 44 & 12 \\
P11 & F & 79 & 96 & 163 & 33 & 6 \\
P12 & M & 78 & 95 & 178 & 27 & 5 \\
\hline
\end{tabular}

The majority of patients were males (83\%). The table shows that patients were selected in stable condition, their transcutaneous oxygen saturation was kept at least above $92 \%$ by adjusting both $\mathrm{FiO}_{2}$ and PEEP at necessary levels.

Inclusion criteria were age $>18$, hypoxaemia $<92 \%$ and $<88 \%$ in patients with risk of hypercapnic respiratory failure. Exclusion criteria were contraindications for non-invasive ventilation (e.g. unstable conditions of upper airways, aspiration risks) and clinical deterioration of patient condition that was decided by study performing physician.

Before the experiment, the arterial catheter has been inserted into a patient's radial artery and the first arterial blood probe has been taken after hypoxaemia was corrected. The examination lasted one hour, each $15 \mathrm{~min}$ the blood probe was repeated and checked for ABG parameters. Straight after or after 15-min break patients have been connected to the new CPAP supplemental oxygen delivery system and $\mathrm{FiO}_{2}$ and PEEP levels have been set similar to the previous instrument. $\mathrm{FiO}_{2}$ and PEEP levels, if necessary, were corrected regarding arterial blood gas analysis and $\mathrm{SpO}_{2}$ measurements.

$\mathrm{SpO}_{2}$ has been monitored continuously, blood gas analysis has been repeated every 15 min ( $\mathrm{pH}, \mathrm{PaO}_{2}, \mathrm{PaCO}_{2}, \mathrm{HCO}_{3}-, \mathrm{SaO}_{2}$ ), blood pressure, heart rate, respiratory rate, with the help of an additional sensor $\mathrm{FiO}_{2}$. With each subsequent device, the PEEP size has been selected the same as with the previous device or its modification.

Research data has been processed using 'MS Excel' and 'SPSS' software by repeatedmeasures analysis of variance ('ANOVA'). The obtained data ( $\mathrm{pH}, \mathrm{PaO}_{2}, \mathrm{PaCO}_{2}, \mathrm{HCO}-$-, $\mathrm{SaO}_{2}$, blood pressure, heart rate, respiratory rate, with the help of an additional sensor $\mathrm{FiO}_{2}$ ) have been compared between all groups.

\footnotetext{
Abbreviations

$\mathrm{AaDO}_{2}$ : Alveolar-arterial gradient of oxygen; ABG: Arterial blood gases; APAP: Automatic positive airway pressure; COVID19: Coronavirus disease 2019; CPAP: Continuous positive airway pressure; $\mathrm{FiO}_{2}$ : Fraction of inspired oxygen; HFNC: High flow nasal cannula; ICU: Intensive care unit; LCD: Liquid-crystal display; NIV: Non-invasive ventilation; OSA: Obstructive sleep apnea; $\mathrm{PaO}_{2}$ : Partial pressure of oxygen in arterial blood; $\mathrm{PaCO}_{2}$ : Partial pressure of carbon dioxide pressure in arterial blood; PEEP: Positive end-expiratory pressure; PID: Proportional-Integral-Derivative (controller); PSCUH: Paul Stradins Clinical University Hospital; $\mathrm{SaO}_{2}$ : Arterial oxygen saturation; $\mathrm{SpO}_{2}$ : Oxygen saturation provided by pulseoxymetry.
}

Acknowledgements

We would like to thank the following for their helpful comments: University of Latvia: Maksims Mastalers, Aleksandra Podhvatilina, Sergejs Lobanovs, Kristina Sauliusa, Olga Matosova, Kaspars Eglītis. We would like also to thank Marek Zevalds 
(VRGO Ltd), Jana Višnevevska (Longenesis Ltd), Arnis Salms (Institute of Electronics and Computer Science), Jānis Zaharns and Jurijs Jonass. We would very much like to thank Ilze Ābolina (PSCUS) for the study coordination.

\section{Authors' contributions}

All authors contributed and reviewed the manuscript. DB, VG, JT, G Z, ES participated in prototype design and bench tests, SK, AS, MP, SJ, DZ, DŽ participated in a clinical trial, VP and IT triple checked all data and provided statistical support. All authors read and approved the final manuscript.

\section{Funding}

Grant "VPP-COVID-2020/1-0025" from Latvian Council of Science.

Availability of data and materials

Not applicable.

\section{Declarations}

Ethics approval and consent to participate

The study was evaluated and received permission from the local Ethics committee of the PSCUH. Nr. 261120-10L

\section{Consent for publication}

We grant exclusive rights on royalty-free basis to BMC Publishing Group Ltd ("BMC") its licensees and where the relevant Journal is co-owned by BMC to the co-owners of the Journal, to publish the Work in Biomedical Engineering Online and to exploit all rights.

\section{Competing interests}

No competing interests.

\section{Author details}

${ }^{1}$ Institute of Smart Computer Technologies, Riga Technical University, 2-335 Daugavgrivas street, Riga 1658, Latvia. ${ }^{2}$ Department of Internal Medicine, Paul Stradins Clinical University Hospital, 13 Pilsonu street, Riga 1002, Latvia. ${ }^{3}$ University of Latvia Institute of Numerical Modelling, 3 Jelgavas street, Riga 1004, Latvia. ${ }^{4}$ Paul Stradins Clinical University Hospital, Research Institute, 13 Pilsonu street, Riga 1002, Latvia. ${ }^{5}$ Faculty of Computing, University of Latvia, 19 Raina bulvaris, Riga 1586, Latvia.

Received: 15 October 2021 Accepted: 24 January 2022

Published online: 04 February 2022

\section{References}

1. Mason RJ. Pathogenesis of COVID-19 from a cell biology perspective. Eur Respir J. 2020;55(4):2000607. https://doi. org/10.1183/13993003.00607-2020.

2. Brusasco C, Corradi F, Di Domenico A, Raggi F, Timossi G, Santori G, Brusasco V. Galliera CPAP-Covid-19 study group; collaborators of the Galliera CPAP-COVID-19 study group are Continuous positive airway pressure in COVID-19 patients with moderate-to-severe respiratory failure. Eur Respir J. 2021;57(2):2002524. https://doi.org/10.1183/13993 003.02524-2020.

3. Tobin MJ. Basing respiratory management of COVID-19 on physiological principles. Am J Respir Crit Care Med. 2020;201(11):1319-20. https://doi.org/10.1164/rccm.202004-1076ED.

4. Gürün Kaya A, Öz M, Erol S, Çiftçi F, Çiledağ A, Kaya A. High flow nasal cannula in COVID-19: a literature review. Tuberk Toraks. 2020;68(2):168-74. https://doi.org/10.5578/tt.69807.

5. Mellado-Artigas R, Ferreyro BL, Angriman F, Hernández-Sanz M, Arruti E, Torres A, Villar J, Brochard L, Ferrando C. COVID-19 Spanish ICU Network High-flow nasal oxygen in patients with COVID-19-associated acute respiratory failure. Crit Care. 2021;25(1):58. https://doi.org/10.1186/s13054-021-03469-w.

6. Carter C, Aedy H, Notter J. COVID-19 disease: Non-Invasive Ventilation and high frequency nasal oxygenation. Clinics Integrated Care. 2020;1: 100006. https://doi.org/10.1016/j.intcar.2020.100006.

7. Ranney ML, Griffeth V, Jha AK. Critical Supply Shortages - The Need for Ventilators and Personal Protective Equipment during the Covid-19 Pandemic. N Engl J Med. 2020;382(18):e41. https://doi.org/10.1056/NEJMp2006141.

8. Intensive Care Society. 2020. Use of continuous positive airway pressure (CPAP) for COVID-19 positive patients. https://icmanaesthesiacovid-19.org/news/use-of-cpap-for-covid-19-positive-patients. Accessed 15 Mar 2021.

9. Gabrielli M, Esperide A, Valletta F, Giancristofaro F, Santoro M, Santarelli L, Franceschi F. Relationship between arterialalveolar oxygen gradient, mortality and admission to intensive care unit in severe covid-19 related pneumonia: a pilot study. Biomed J Sci Techn Res. 2020;31:23864-8.

10. Carteaux G, Pons M, Morin F, Tuffet S, Lesimple A, Badat B, Haudebourg AF, Perier F, Deplante Y, Guillaud C, Schlemmer F, Fois E, Mongardon N, Khellaf M, Jaffal K, Deguillard C, Grimbert P, Huguet R, Razazi K, de Prost N, Templier F, Beloncle F, Mercat A, Brochard L, Audard V, Lim P, Richard JC, Savary D, Mekontso DA. Continuous positive airway pressure for respiratory support during COVID-19 pandemic: a frugal approach from bench to bedside. Ann Intensive Care. 2021;11(1):38. https://doi.org/10.1186/s13613-021-00828-2.

11. MIT. MIT-based team works on rapid deployment of open-source low-cost ventilator. news.mit.edu/2020/ventilatorcovid-deployment-open-source-low-cost-0326. Accessed 15 Mar 2021.

12. Nvidia. NVIDIA Chief Scientist Releases Low-Cost, Open-Source Ventilator Design. blogs.nvidia.com/ blog/2020/05/01/low-cost-open-source-ventilator-nvidia-chief-scientist. Accessed 15 Mar 2021. 
13. Dex. Emergency lung ventilator. dex-ic.com/emergency-lung-ventilator. Accessed 15 Mar 2021.

14 Suzumura EA, Zazula AD, Moriya HT, Fais CQA, Alvarado AL, Cavalcanti AB, Rodrigues RG. Challenges for the development of alternative low-cost ventilators during COVID-19 pandemic in Brazil. Rev Bras Ter Intensiva. 2020;32(3):444-57. https://doi.org/10.5935/0103-507X.20200075.

15. Vasan A, Weekes R, Connacher W, Sieker J, Stambaugh M, Suresh P, Lee DE, Mazzei W, Schlaepfer E, Vallejos T, Petersen J, Merritt S, Petersen L, Friend J. MADVent: A low-cost ventilator for patients with COVID-19. Med Devices Sens. 2020. https://doi.org/10.1002/mds3.10106.

16. Garmendia O, Rodríguez-Lazaro MA, Otero J, Phan P, Stoyanova A, Dinh-Xuan AT, Gozal D, Navajas D, Montserrat JM, Farré R. Low-cost, easy-to-build noninvasive pressure support ventilator for under-resourced regions: open source hardware description, performance and feasibility testing. Eur Respir J. 2020;55(6):2000846. https://doi.org/10.1183/ 13993003.00846-2020.

17. Ashish A, Unsworth A, Martindale J, Sundar R, Kavuri K, Sedda L, Farrier M. CPAP management of COVID-19 respiratory failure: a first quantitative analysis from an inpatient service evaluation. BMJ Open Respir Res. 2020;7(1): e000692. https://doi.org/10.1136/bmjresp-2020-000692.

18. Attaway AH, Scheraga RG, Bhimraj A, Biehl M, Hatipoğlu U. Severe covid-19 pneumonia: pathogenesis and clinical management. BMJ. 2021;10(372): n436. https://doi.org/10.1136/bmj.n436.

19. Pandor A, Thokala P, Goodacre S, Poku E, Stevens JW, Ren S, Cantrell A, Perkins GD, Ward M, Penn-Ashman J. Prehospital non-invasive ventilation for acute respiratory failure: a systematic review and cost-effectiveness evaluation. Health Technol Assess. 2015;19(42):1-102. https://doi.org/10.3310/hta19420.

20. Mahase E. Covid-19: Mercedes F1 to provide breathing aid as alternative to ventilator. BMJ. 2020;30(368): m1294. https://doi.org/10.1136/bmj.m1294.

21 Singer M, Shipley R, Baker T, Cowell A, Brealey D, Lomas D. The UCL Ventura CPAP device for COVID-19. Lancet Respir Med. 2020;8(11):1076-8. https://doi.org/10.1016/S2213-2600(20)30422-7.

22. BBC. Covid-19: Southend Hospital oxygen supply reaches 'critical' situation. 2021. https://www.bbc.com/news/ukengland-essex-55615591. Accessed 16 Mar 2021.

23. American Association for Respiratory Care. Additional Ventilators May Pose a Risk to Hospital Gas Systems. 2020. https://www.aarc.org/additional-ventilators-may-pose-risk-to-hospital-gas-systems/. Accessed 16 Mar 2021.

24. Pavwoski P, Shelgikar AV. Treatment options for obstructive sleep apnea. Neurol Clin Pract. 2017;7(1):77-85. https:// doi.org/10.1212/CPJ.0000000000000320.

25. Gottlieb DJ, Punjabi NM. Diagnosis and management of obstructive sleep apnea: a review. JAMA. 2020;323(14):1389-400. https://doi.org/10.1001/jama.2020.3514.

26 Petersson J, Glenny RW. Gas exchange and ventilation-perfusion relationships in the lung. Eur Respir J. 2014:44:1023-41.

\section{Publisher's Note}

Springer Nature remains neutral with regard to jurisdictional claims in published maps and institutional affiliations.

- fast, convenient online submission

- thorough peer review by experienced researchers in your field

- rapid publication on acceptance

- support for research data, including large and complex data types

- gold Open Access which fosters wider collaboration and increased citations

- maximum visibility for your research: over $100 \mathrm{M}$ website views per year

At BMC, research is always in progress.

Learn more biomedcentral.com/submissions 